\title{
Papers
}

\section{Vulnerability to winter mortality in elderly people in Britain: population based study}

Paul Wilkinson, Sam Pattenden, Ben Armstrong, Astrid Fletcher, R Sari Kovats, Punam Mangtani, Anthony J

McMichael

\begin{abstract}
Objective To examine the determinants of vulnerability to winter mortality in elderly British people.

Design Population based cohort study (119 389 person years of follow up).

Setting 106 general practices from the Medical Research Council trial of assessment and management of older people in Britain.

Participants People aged $\geq 75$ years.

Main outcome measures Mortality (10 123 deaths) determined by follow up through the Office for National Statistics.

Results Month to month variation accounted for $17 \%$ of annual all cause mortality, but only $7.8 \%$ after adjustment for temperature. The overall winter:non-winter rate ratio was 1.31 (95\% confidence interval 1.26 to 1.36 ). There was little evidence that this ratio varied by geographical region, age, or any of the personal, socioeconomic, or clinical factors examined, with two exceptions: after adjustment for all major covariates the winter:non-winter ratio in women compared with men was 1.11 (1.00 to 1.23), and those with a self reported history of respiratory illness had a winter:non-winter ratio of 1.20 (1.08 to 1.34) times that of people without a history of respiratory illness. There was no evidence that socioeconomic deprivation or self reported financial worries were predictive of winter death.

Conclusion Except for female sex and pre-existing respiratory illness, there was little evidence for vulnerability to winter death associated with factors thought to lead to vulnerability. The lack of socioeconomic gradient suggests that policies aimed at relief of fuel poverty may need to be supplemented by additional measures to tackle the burden of excess winter deaths in elderly people.
\end{abstract}

\section{Introduction}

In the United Kingdom mortality greatly increases in winter. ${ }^{1}$ This is apparent at all ages but is greatest in relative and absolute terms in elderly people. ${ }^{23}$ Much of the excess seems to be related to cold, ${ }^{45}$ yet Britain has a larger seasonal fluctuation in mortality than many other countries of continental Europe and Scandinavia despite having milder winters. ${ }^{6}$ Behavioural factors may partly explain this, ${ }^{7}$ but poor housing may also be important. ${ }^{2}$ To date there have been few opportunities to examine the personal factors that predispose to increased mortality in winter.

We studied mortality in people aged $\geq 75$ years, focusing on individual determinants of vulnerability, including socioeconomic factors, sex, home heating, and previous health.

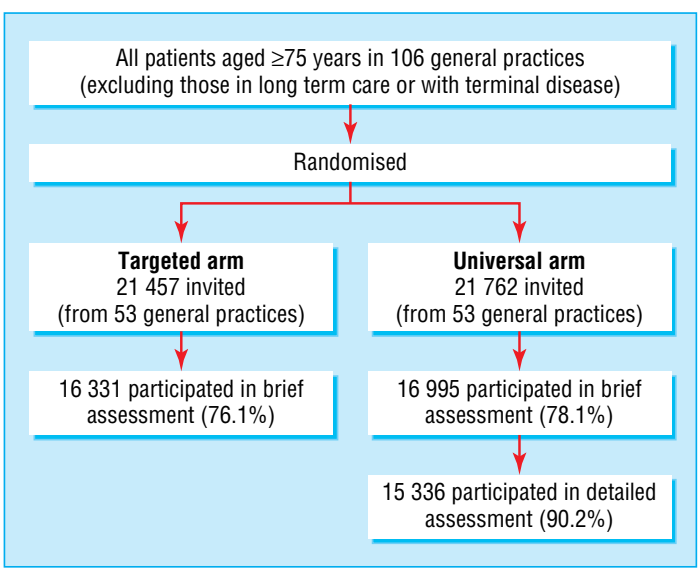

Fig 1 Practices and patients participating in MRC trial of assessment and management of older people in the community

\section{Methods}

The study was based on the Medical Research Council trial of the assessment and management of older people in the community, ${ }^{8}$ which involved 106 practices selected from the MRC general practice research framework as representative of the British population. All patients aged $\geq 75$ years on practice lists were invited to participate unless they were in a long stay hospital or nursing home or were terminally ill. Practices were randomised to targeted or universal screening (fig 1). Participants, recruited in 1995-8, underwent a brief multidimensional assessment; those in the universal screening arm were also assessed in detail by the study nurse, along with those from the targeted arm who had a predetermined number and range of problems on the brief assessment. We have not presented the results of detailed assessments in the targeted arm here as the sample was not representative.

The brief assessment included questions on physical symptoms, number of medications, feelings of depression, activities of daily living, perceived health, and physical activity. Patients were asked about their current alcohol intake, smoking, sociodemographic factors (including marital status, living circumstances, financial difficulties), and home heating ("In the last year have you had difficulty keeping your home warm?" and (in the detailed assessment only) "Do you have central heating?"). The detailed assessment also covered respiratory symptoms (MRC respiratory questionnaire), angina (Rose chest pain questionnaire), cognitive function (mini-mental state examination), geriatric depression scale, and medical history, including data on 
heart attack, stroke, cancer, and diabetes. Data on social class were available for only a small subset of participants (and were not used in the main analysis) and on housing tenure only for those with detailed assessment. To provide socioeconomic data for the full sample, we used the home postcode to assign a Carstairs deprivation score to each individual, calculated from 1991 census data, for his or her enumeration district of residence (around 140 households per enumeration district). ${ }^{9}$

We followed up mortality (to 30 March 2001) through the Office for National Statistics. As an index of circulating influenza, we obtained weekly counts of clinical specimens of influenza A reported to the Public Health Laboratory Service. We obtained figures for daily minimum, maximum, and mean temperature from one meteorological station per region from the British Atmospheric Data Centre.

\section{Statistical methods}

We used Poisson time series models to assess overall effects of season (month of years as categorical variable), temperature, and influenza. ${ }^{10}$ Individual days at risk and deaths were aggregated into regional daily series, and linked to regional weather and national influenza series. Death rates were modelled as log linear functions of temperature and influenza counts. Proportions of deaths attributable to each explanatory variable were estimated with the approach of Bruzzi et al. ${ }^{11}$

To analyse excess mortality in the winter season, we defined winter as December to March, following Curwen. ${ }^{1}$ (These are the coldest months and contain most of the days with maximum temperature below $5^{\circ} \mathrm{C}$.) We used tabulation and Poisson regression with interaction terms to analyse the extent to which the ratio of deaths in winter to deaths at other times was modified by individual characteristics. We divided each participant's time at risk into winter and non-winter periods. For analyses that did not require information collected at the baseline interview, we considered that participants were at risk from the date they were invited to participate; for analyses that required data from the brief or detailed questionnaire, they were considered at risk from the date of interview plus six weeks to limit potential bias due to "healthy participant" selection. Non-participants were more likely to have died within the first six months of follow up (odds ratio $3.01,95 \%$ confidence interval 2.50 to 3.62 ) and on average were older ( 81.8 years) than participants (81.2 years). When the date of interview was missing $(\mathrm{n}=497)$, we assumed it to be 14 days after the date of invitation-the mean among other participants.

For the main results, the Poisson models included age (four groups), sex, and region and interactions of these with winter. (Estimates of the influence of each of these factors on the winter:non-winter ratio are therefore adjusted for the influence of the other two.) Thus, we tabulated the winter:non-winter ratio for each level (group) of each explanatory variable, and then the ratio of these winter:non-winter ratios relative to that of the baseline group. The latter can be thought of as "relative risks" of excess winter death. They are in fact the exponentiated coefficients of the interaction terms of the relevant variable with the winter indicator-with age, sex, and region and their corresponding interactions with winter also included in the model.

Although influenza vaccine modified the association of mortality with periods of high flu transmission, vaccination did not confound the associations examined here. We estimated standard errors and confidence intervals using the Huber-White "sandwich" estimator ${ }^{12}$ grouping by practice.
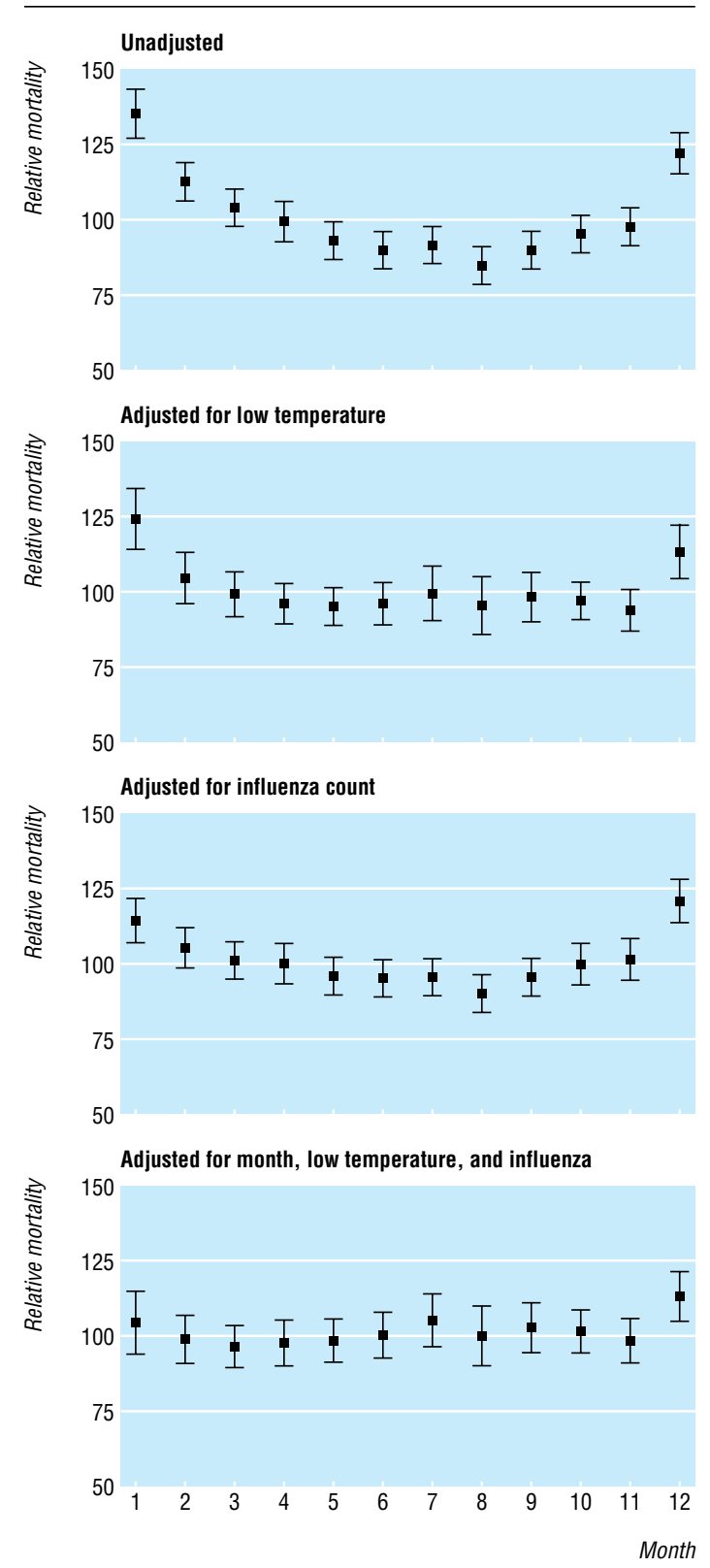

Fig 2 Fraction of deaths attributable to monthly variation, adjusted for region, time trend, and stated covariates

\section{Results}

Month to month variation in mortality (adjusted for region and time trend) accounted for $17 \%$ of annual all cause mortality, but only $7.8 \%$ after adjustment for the effects of low temperatures (fitted as the mean temperature over the index and previous 13 days) in the daily time series model (fig 2). It accounted for $12.6 \%$ when we adjusted for influenza A counts without adjustment for low temperature, and 5.2\% when we adjusted for both. Thus, most of the seasonal fluctuation seems to be related to cold, with smaller components attributable to influenza $\mathrm{A}$ and other risk factors.

Overall, there were 4221 deaths in 42162 person years of follow up in winter months (100.1 deaths per 1000 person years, 95\% confidence interval 97.1 to 103.1) and 5902 in 77227 person years of follow up in other months (76.4 deaths per 1000 person years, 74.5 to 78.4 ). 
All analysed variables showed an association with the absolute risk of death in both winter and non-winter months, though there was little difference with factors listed as home circumstances (living alone, reported difficulty making ends meet, and difficulty keeping the house warm) (table 1).

The overall winter:non-winter rate ratio was 1.31 (1.26 to 1.36), which is slightly higher than that found in this age group in the country as a whole. ${ }^{2}$ There was little evidence that this ratio varied by geographical region or age (table 1). Women, however, had a larger winter:non-winter ratio than men for reasons other than their greater age, previous health status, social isolation, or socioeconomic position (table 2 ).

There was little evidence of a trend of increasing risk of excess winter death with socioeconomic group, housing tenure (not tabulated), or reported difficulty in making ends meet or in keeping the house warm. Nor was there clear evidence that the combination of low socioeconomic group and reported difficulty in keeping the house warm (a combination expected to identify people least able to heat their home properly) was associated with excess risk (table 3). Those who lived alone seemed no more vulnerable than others.

Of the various markers of illness and activity status (table 1), only a history of respiratory illness was associated with winter death; the relative risk adjusted for age, sex, and region being 1.20 (1.08 to 1.34). There was no evidence that excess winter death was associated with current smoking, total pack years of cigarettes smoked (not shown), or alcohol consumption. The more detailed assessment of mental health showed no association of the winter ratio with cognitive impairment (minimental state examination $<17$ ) or depression (geriatric depression scale $\geq 6$ ).

For most variables, the confidence intervals provide evidence against a substantial increase in risk (most exclude increases above 10\%). The exceptions include: often having difficulty keeping the house warm (1.14 (0.89 to 1.46), the upper confidence limit for which is compatible with an appreciable increase), frailty, shortness of breath, a history of cardiovascular disease, and consumption of $\geq 7$ units of alcohol a week.

Pre-existing respiratory disease (asthma, emphysema, or pneumonia diagnosed by a doctor, or a positive response to questions on chronic cough or phlegm) was the single strongest predictor of excess winter death (table 4). It was most clearly associated with death from cardiovascular disease. The ratio of winter:non-winter cardiovascular mortality in those with respiratory disease relative to those without was 1.23 (1.02 to 1.47), and this figure varied only slightly with adjustment for different combinations of potential confounding factors (results not tabulated). History of wheeze or asthma or pneumonia in particular seemed to contribute to this higher relative risk, though history of phlegm for three months a year (a marker of chronic obstructive airways disease) did not. In contrast, there was no evidence that pre-existing respiratory illness increased excess respiratory death, nor that cardiovascular illness increased excess cardiovascular death. The finding that death from non-cardiorespiratory causes was greater in participants with a history of myocardial infarction is noteworthy but may be due to chance.

\section{Discussion}

This study is the first large scale epidemiological study in elderly people to have examined variation in excess winter death in relation to risk factors defined at the individual level. Its focus on people of $\geq 75$ years is important because they are particularly vulnerable to winter death. ${ }^{2} 1314$

The results confirm a substantial (around 30\%) increase in mortality in winter in this age group, but, remarkably, they point to few of the analysed factors being markers of vulnerability except pre-existing respiratory disease and female sex. The higher risk in women is not fully explained but does not seem to be due to clinical or socioeconomic differences.

\section{The role of socioeconomic status}

Some of the factors that were unrelated to excess winter death merit comment, especially as many of them were associated with overall mortality, so poor validity is unlikely to explain the lack of association. Perhaps most surprising is socioeconomic status, which showed no gradient in risk, despite the fact that the Carstairs score was a predictor of death rates overall (table 1), as would be expected from other published studies. ${ }^{15}$ Scrutiny of the literature, however, shows that the lack of socioeconomic gradient with winter death has been a consistent finding of UK studies. ${ }^{214}{ }^{16-18}$ If there is a gradient in risk, it is small.

This is a conclusion that policy makers may find unexpected and at odds with current notions of vulnerability from fuel poverty. The explanation may be complex. Firstly, although lower socioeconomic groups have high mortality in absolute terms, it is not obvious that they should also have a high relative increase in deaths during winter months unless they are more exposed to the principal causes of it-specifically low ambient temperature. But we have previously shown that people in lower socioeconomic groups do not on average have cooler homes than people in higher socioeconomic groups. ${ }^{2}$ This may reflect behavioural influences, but also the fact that housing association and local authority dwellings are often as well, or better, heated than owner occupied dwellings, ${ }^{2}$ reflecting the relatively recent construction of much social housing and efforts by local authorities to improve home energy efficiency. Poverty is associated with poorer home heating when heating costs are high, so the lack of increased risk among those reporting difficulty in making ends meet and difficulty in keeping the home warm is surprising, although the results are compatible with an appreciable increase in risk in relation to the latter variable. It could be argued that reported difficulty in keeping the home warm is not a good indicator of low indoor temperatures (though in fact we have found it predictive in a previous study), ${ }^{2}$ and that reported difficulty in making ends meet might not be sensitive for poverty. However, Keatinge and colleagues place more emphasis on personal behaviours and have argued that much excess winter mortality is related to exposure to cold from "brief excursions outdoors rather than to low indoor temperatures." 19 The observed lack of socioeconomic gradient suggests that the risk of excess winter death is quite widely distributed in elderly people, which therefore may limit the potential health impacts of initiatives that are targeted only at low income households. Of course, the situation may be different in other age groups, but it is relevant to recall the relative flatness of excess winter mortality with socioeconomic status in other UK studies not specific to this age group.

\section{The role of pre-existing illness}

The fact that frailty and pre-existing cardiovascular illness were unrelated to excess winter death was also surprising as most winter deaths are from cardiorespiratory causes. Paradoxically, respiratory disease seemed to be a strong determinant of cardiovascular but not respiratory death. The specificity of association may have been obscured by misclassification of cause of death, but analyses (not shown) of deaths with any mention of 
Table 1 Rates of death in winter and non-winter months, ratio of rates, and relative change in winter:non-winter ratios with levels of potential modifying factors

Variable (potential modifiers of

Rate per 1000 person years (No of deaths) winter:non-winter ratio)

Winter months

Non-winter months

Winter:non-winter ratio $(95 \% \mathrm{CI})$ Unadjusted

Winter:non-winter ratio relative to ratio Brief questionnaire

All people $100.1(4221) \quad 76.4(5902)$ 1.31 (1.26 to 1.36$)$

\section{Sociodemographic factors and personal behaviours}

Age (years):

\begin{tabular}{|c|c|c|c|c|}
\hline $75-79$ & 62.1 (1318) & 48.5 (1874) & 1.28 (1.19 to 1.38$)$ & 1.00 \\
\hline $80-84$ & $102.5(1343)$ & $80.2(1928)$ & 1.28 (1.20 to 1.36$)$ & 0.99 (0.91 to 1.09) \\
\hline $85-89$ & $175.0(1050)$ & $124.8(1390)$ & 1.40 (1.29 to 1.52$)$ & 1.09 (0.98 to 1.21$)$ \\
\hline$\geq 90$ & $279.1(510)$ & $207.3(710)$ & 1.35 (1.20 to 1.51$)$ & $1.03(0.92$ to 1.16$)$ \\
\hline \multicolumn{5}{|l|}{ Sex: } \\
\hline Male & $115.3(1745)$ & 92.7 (2578) & 1.24 (1.17 to 1.32$)$ & 1.00 \\
\hline Female & $91.6(2476)$ & 67.3 (3324) & 1.36 (1.29 to 1.44$)$ & 1.09 (1.01 to 1.17$)$ \\
\hline \multicolumn{5}{|l|}{ Region: } \\
\hline East Scotland & 100.7 (265) & $75.9(365)$ & 1.33 (1.04 to 1.69$)$ & 1.00 \\
\hline West Scotland & $114.0(204)$ & $78.9(259)$ & 1.45 (1.35 to 1.55$)$ & 1.09 (0.85 to 1.41$)$ \\
\hline Wales & $90.4(159)$ & $64.9(206)$ & 1.39 (1.16 to 1.67$)$ & 1.05 (0.78 to 1.42$)$ \\
\hline Northern and Yorkshire & $103.0(726)$ & $80.1(1044)$ & 1.28 (1.11 to 1.49$)$ & 0.97 (0.73 to 1.29$)$ \\
\hline Trent & $110.3(339)$ & $77.6(434)$ & $1.42(1.27$ to 1.59$)$ & 1.07 (0.82 to 1.40$)$ \\
\hline West Midlands & $93.7(412)$ & $77.7(629)$ & 1.21 (1.06 to 1.37$)$ & 0.91 (0.70 to 1.20$)$ \\
\hline North West & $107.8(361)$ & $82.2(505)$ & 1.31 (1.15 to 1.49$)$ & $0.99(0.75$ to 1.30$)$ \\
\hline Eastern & $97.3(323)$ & $74.9(458)$ & 1.30 (1.10 to 1.53$)$ & 0.98 (0.73 to 1.32$)$ \\
\hline London & $99.9(352)$ & $77.3(501)$ & 1.29 (1.13 to 1.47$)$ & 0.98 (0.74 to 1.29$)$ \\
\hline South East & $89.3(578)$ & 68.1 (794) & 1.31 (1.16 to 1.49$)$ & 0.99 (0.75 to 1.30$)$ \\
\hline South West & $104.7(502)$ & $80.0(707)$ & 1.31 (1.17 to 1.46$)$ & 0.99 (0.76 to 1.29) \\
\hline \multicolumn{5}{|c|}{ Fifths of Carstairs deprivation group: } \\
\hline 1 (least deprived) & $92.9(881)$ & $66.5(1151)$ & $1.40(1.26$ to 1.55$)$ & 1.00 \\
\hline 2 & $97.1(1014)$ & $77.5(1483)$ & 1.25 (1.15 to 1.36$)$ & 0.90 (0.78 to 1.02$)$ \\
\hline 3 & $96.4(743)$ & $76.1(1076)$ & $1.27(1.15$ to 1.40$)$ & 0.90 (0.78 to 1.05$)$ \\
\hline 4 & $99.1(552)$ & $81.1(826)$ & $1.22(1.08$ to 1.39$)$ & $0.86(0.72$ to 1.04$)$ \\
\hline 5 (most deprived) & $121.4(464)$ & $83.7(591)$ & 1.45 (1.31 to 1.61$)$ & $1.02(0.87$ to 1.19$)$ \\
\hline \multicolumn{5}{|l|}{ Current smoker: } \\
\hline No & 97.4 (3711) & 73.7 (5144) & 1.32 (1.26 to 1.38$)$ & 1.00 \\
\hline Yes & $127.1(476)$ & $101.7(702)$ & 1.25 (1.11 to 1.41$)$ & 0.96 (0.85 to 1.07$)$ \\
\hline \multicolumn{5}{|l|}{ Alcoholic drinks (units)/week: } \\
\hline 0 & $113.5(2205)$ & $85.8(3059)$ & 1.32 (1.23 to 1.42$)$ & 1.00 \\
\hline $1-6$ & $84.6(1098)$ & $65.9(1564)$ & 1.28 (1.18 to 1.39$)$ & 0.99 (0.89 to 1.11$)$ \\
\hline$\geq 7$ & $90.9(716)$ & $68.7(991)$ & 1.32 (1.19 to 1.48$)$ & 1.04 (0.91 to 1.19) \\
\hline \multicolumn{5}{|c|}{ Markers of illness and activity status } \\
\hline \multicolumn{5}{|c|}{ Shortness of breath†: } \\
\hline No & $90.6(3255)$ & $70.2(4616)$ & 1.29 (1.22 to 1.36$)$ & 1.00 \\
\hline Yes & $166.5(728)$ & $122.9(996)$ & $1.35(1.22$ to 1.51$)$ & $1.04 \quad(0.92$ to 1.17$)$ \\
\hline \multicolumn{5}{|l|}{ Swelling of legs: } \\
\hline No & 94.9 (3567) & 72.2 (4968) & 1.31 (1.25 to 1.39$)$ & 1.00 \\
\hline Yes & $155.3(478)$ & $119.8(679)$ & 1.30 (1.15 to 1.46$)$ & 0.96 (0.84 to 1.10$)$ \\
\hline \multicolumn{5}{|c|}{ Sad, depressed, or miserable: } \\
\hline No & 96.1 (3661) & $73.4(5118)$ & 1.31 (1.25 to 1.37$)$ & 1.00 \\
\hline Yes & $135.3(465)$ & $104.0(658)$ & 1.30 (1.17 to 1.45$)$ & 0.98 (0.88 to 1.10$)$ \\
\hline \multicolumn{5}{|l|}{ Not very or at all active: } \\
\hline No & 76.4 (2601) & $57.6(3577)$ & 1.33 (1.25 to 1.40$)$ & 1.00 \\
\hline Yes & $201.6(1581)$ & $155.8(2275)$ & 1.29 (1.21 to 1.39$)$ & 0.95 (0.87 to 1.04$)$ \\
\hline \multicolumn{5}{|l|}{ Takes >5 medicines: } \\
\hline No & $88.3(3085)$ & $67.1(4287)$ & 1.32 (1.24 to 1.39$)$ & 1.00 \\
\hline Yes & $160.7(960)$ & 122.5 (1349) & 1.31 (1.21 to 1.42$)$ & 0.99 (0.90 to 1.09$)$ \\
\hline \multicolumn{5}{|l|}{ Home circumstances } \\
\hline \multicolumn{5}{|l|}{ Lives alone: } \\
\hline No & $100.5(2257)$ & $76.2(3135)$ & 1.32 (1.25 to 1.39$)$ & 1.00 \\
\hline Yes & $97.2(1871)$ & 74.8 (2636) & 1.30 (1.22 to 1.38$)$ & 0.94 (0.88 to 1.02) \\
\hline \multicolumn{5}{|l|}{ Difficulty making ends meet: } \\
\hline No & $99.3(3541)$ & $75.2(4910)$ & 1.32 (1.26 to 1.39$)$ & 1.00 \\
\hline Yes & $96.0(547)$ & $75.2(786)$ & 1.28 (1.16 to 1.40$)$ & 0.96 (0.88 to 1.06$)$ \\
\hline \multicolumn{5}{|c|}{ Difficulty keeping house warm: } \\
\hline No & $99.2(3507)$ & 75.7 (4891) & 1.31 (1.25 to 1.38$)$ & 1.00 \\
\hline Sometimes & $96.9(487)$ & $75.0(696)$ & 1.29 (1.14 to 1.46$)$ & 0.98 (0.87 to 1.11$)$ \\
\hline Often & $109.8(135)$ & $73.0(166)$ & 1.50 (1.19 to 1.89$)$ & 1.14 (0.89 to 1.46$)$ \\
\hline
\end{tabular}


Detailed questionnaire

\begin{tabular}{|c|c|c|c|c|}
\hline All persons & 99.9 (2071) & 78.9 (2982) & 1.27 (1.20 to 1.34$)$ & - \\
\hline \multicolumn{5}{|c|}{ Markers of illness } \\
\hline \multicolumn{5}{|c|}{ Frailł: } \\
\hline No & $51.5(516)$ & 41.4 (752) & 1.24 (1.13 to 1.37$)$ & 1.00 \\
\hline Yes & 133.0 (1211) & 103.2 (1719) & 1.29 (1.18 to 1.41$)$ & $1.03(0.89$ to 1.19$)$ \\
\hline \multicolumn{5}{|c|}{ Respiratory illness§: } \\
\hline No & 75.0 (691) & 66.4 (1114) & 1.13 (1.03 to 1.24$)$ & 1.00 \\
\hline Yes & 119.6 (1374) & $88.8(1861)$ & 1.35 (1.24 to 1.46$)$ & 1.20 (1.08 to 1.34$)$ \\
\hline \multicolumn{5}{|c|}{ Cardiovascular illnessfl: } \\
\hline No & 87.7 (1403) & 68.6 (1995) & 1.28 (1.17 to 1.40$)$ & 1.00 \\
\hline Yes & 140.7 (663) & $113.3(980)$ & 1.24 (1.10 to 1.40$)$ & 0.97 (0.84 to 1.13$)$ \\
\hline
\end{tabular}

* Adjusted for age, sex, region. Ratios are "relative risks" of excess winter death compared with baseline group. Specifically, they are exponentiated coefficients of interaction terms of listed variable with "winter" indicator (with age, sex, and region and their interactions with "winter" also in model).

tWhen sitting or talking.

†Poor perceived health, not very/at all active, in lowest fifth of body mass index, or unable to do $\geq 2$ activities of daily living.

$\S$ Asthma, emphysema, or pneumonia diagnosed by doctor, or positive response to questions on chronic cough or phlegm.

IHeart attack or stroke diagnosed by doctor, or positive result on Rose angina questionnaire.

Table 2 Rate ratios (95\% confidence intervals) for excess winter death, all causes: women relative to men*

\begin{tabular}{|c|c|}
\hline Adjustment & Rate ratio $(95 \% \mathrm{Cl})$ \\
\hline \multicolumn{2}{|l|}{ Brief questionnaire } \\
\hline Unadjusted & 1.09 (0.99 to 1.19$)$ \\
\hline Region, age & $1.08(0.99$ to 1.19$)$ \\
\hline Above plus takes $>5$ medications, SOB, SOA & 1.08 (0.98 to 1.18$)$ \\
\hline $\begin{array}{l}\text { Above plus lives alone, Carstairs deprivation } \\
\text { group }\end{array}$ & 1.11 (1.01 to 1.23$)$ \\
\hline $\begin{array}{l}\text { Above plus difficulty making ends meet, } \\
\text { difficulty keeping house warm }\end{array}$ & 1.11 (1.00 to 1.23$)$ \\
\hline \multicolumn{2}{|l|}{ Detailed questionnaire } \\
\hline $\begin{array}{l}\text { Region, age, takes }>5 \text { medications, SOB, } \\
\text { SOA, lives alone, Carstairs deprivation } \\
\text { group, difficulty making ends meet, } \\
\text { difficulty keeping house warm } \\
\end{array}$ & 1.11 (0.96 to 1.28$)$ \\
\hline $\begin{array}{l}\text { Above plus pre-existing respiratory illness, } \\
\text { heart attack, angina, or stroke }\end{array}$ & $1.12(0.98$ to 1.29$)$ \\
\hline \multicolumn{2}{|c|}{$\begin{array}{l}\mathrm{SOB}=\text { shortness of breath when sitting or talking; } \mathrm{SOA}=\text { swelling of ankles. } \\
{ }^{*} \mathrm{To} \text { avoid variation in numbers between rows, analyses were restricted to participants with } \\
\text { complete information on all analysed brief questionnaire variables }(\mathrm{n}=25 \text { 907) or on all } \\
\text { analysed detailed questionnaire variables }(\mathrm{n}=12781) \text {. This leads to some difference in results } \\
\text { adjusted for age and region compared with those in table } 1 \text {. }\end{array}$} \\
\hline
\end{tabular}

Table 3 Rate ratios (95\% confidence interval) for excess winter death (all causes) in relation to difficulty keeping house warm and Carstairs deprivation group, adjusted for age, sex, and region

\begin{tabular}{lcc}
\multirow{2}{*}{$\begin{array}{l}\text { Difficulty keeping house } \\
\text { warm }\end{array}$} & \multicolumn{2}{c}{ Deprivation group } \\
\cline { 2 - 3 } & Least deprived 20\% & Most deprived 20\% \\
\hline No & 1.0 & $0.86(0.69$ to 1.06$)$ \\
\hline Yes & $1.24(0.97$ to 1.60$)$ & $0.79(0.57$ to 1.07$)$ \\
\hline
\end{tabular}

respiratory causes also did not show an association with pre-existing respiratory illness. How lung disease might contribute to excess cardiovascular death is unclear given that much of the risk related to cold probably occurs through haemodynamic and thrombotic mechanisms ${ }^{20-23}$ as a result of body cooling. ${ }^{24}{ }^{25}$ Respiratory disease could be a marker of another factor, such as smoking, but we found no association between smoking and excess winter death. Of course, chance is a possible explanation for some of the apparent cause specific associations.

\section{Conclusion}

In conclusion, we have provided rare individual level evidence on risk factors for excess winter death in elderly people in the United Kingdom. We found little evidence for vulnerability to winter death associated with factors previously thought to predict such vulnerability. The lack of socioeconomic gradient in particular has implications for public heath policies aimed at reducing the burden of winter death, as fuel poverty relief alone may be only partially successful. The fact that the risk of excess winter death seems to be widely distributed in elderly people suggests that additional measures are needed to reach all those at risk.

We thank Chris Bulpitt, Dee Jones, and Alistair Tulloch, coinvestigators on the MRC trial of assessment and management of older people; the nurses, general practitioners, the other staff, and the patients in the participating practices; the MRC general practice research framework coordinating centre, particularly Madge Vickers, Jeannett Martin, and Nicky Fasey; the research team for the MRC trial of assessment and management of older people in the community-Elizabeth Breeze, Edmond Ng, Gill Price, Susan Stirling, Rakhi Kabiwala, and Janbibi Mazar at London School of Hygiene

Table 4 Rate ratios ( $95 \%$ confidence intervals) for excess winter death associated with markers of pre-existing medical illness. All rate ratios adjusted for region, age, sex, and fifth of Carstairs deprivation score

\begin{tabular}{|c|c|c|c|c|}
\hline Evidence of pre-existing illness & All causes & Cardiovascular disease & Respiratory disease & Non-cardiorespiratory illness \\
\hline $\begin{array}{l}\text { Winter and non-winter death rates } \\
\text { (/1000/year) }\end{array}$ & $99.9 / 78.9$ & 44.9 / 38.1 & $21.3 / 12.3$ & $33.7 / 28.5$ \\
\hline Ratio of winter:non-winter rates & 1.27 (1.20 to 1.34$)$ & 1.18 (1.08 to 1.28$)$ & 1.74 (1.52 to 1.97$)$ & 1.18 (1.07 to 1.30$)$ \\
\hline \multicolumn{5}{|l|}{ Cardiovascular illness*: } \\
\hline Any & 0.95 (0.82 to 1.11$)$ & 0.91 (0.75 to 1.12$)$ & 1.12 (0.78 to 1.60$)$ & 0.98 (0.79 to 1.21$)$ \\
\hline Heart attack & 1.08 (0.89 to 1.31$)$ & 0.93 (0.71 to 1.21$)$ & 1.27 (0.81 to 1.99$)$ & 1.53 (1.10 to 2.13$)$ \\
\hline Stroke & 0.86 (0.75 to 0.99$)$ & 0.83 (0.67 to 1.04$)$ & 0.94 (0.60 to 1.46$)$ & 0.92 (0.68 to 1.24$)$ \\
\hline \multicolumn{5}{|l|}{ Respiratory illnesst: } \\
\hline Any & 1.18 (1.04 to 1.34$)$ & 1.23 (1.02 to 1.47$)$ & 0.90 (0.64 to 1.27 ) & 1.16 (0.96 to 1.41$)$ \\
\hline Phlegm for 3 months/year & 1.07 (0.91 to 1.24$)$ & $1.01(0.80$ to 1.29$)$ & 0.92 (0.65 to 1.32$)$ & 1.22 (0.87 to 1.72$)$ \\
\hline Wheeze & 1.29 (1.06 to 1.56$)$ & 1.31 (1.04 to 1.66$)$ & 1.03 (0.72 to 1.46$)$ & 1.30 (0.95 to 1.77$)$ \\
\hline Had asthma & 1.18 (1.00 to 1.39$)$ & 1.25 (0.97 to 1.62$)$ & 1.08 (0.78 to 1.49$)$ & 0.96 (0.70 to 1.34$)$ \\
\hline Had pneumonia & 1.20 (1.01 to 1.43$)$ & 1.24 (0.97 to 1.59$)$ & 1.15 (0.82 to 1.63$)$ & 1.09 (0.82 to 1.43$)$ \\
\hline
\end{tabular}

*Heart attack or stroke diagnosed by doctor, or positive response on Rose angina questionnaire.

†Asthma, emphysema, or pneumonia diagnosed by doctor, or positive response to questions on chronic cough or phlegm. 


\section{What is already known on this topic}

Britain has a large burden of excess winter deaths, much of which is attributable to the effects of cold

Around 1.4 to 2 million households in England are in fuel poverty - that is, they would have to spend more than $10 \%$ of their income to heat the home to an adequate temperature

\section{What this study adds}

Socioeconomic factors are not strongly associated with winter death in elderly people

Female sex and a history of respiratory illness may confer vulnerability

The risk of winter death seems to be widely distributed in elderly people rather than being heavily concentrated in the most disadvantaged groups

Public heath policies to reduce the burden of winter death in Britain will need to be broad based and to consider measures additional to those aimed at tackling fuel poverty

and Tropical Medicine, and Maria Nunes and Ruth Peters at Imperial college; Amina Latif and Elaine Stringer, University of Wales College of Medicine; and the trial steering committee, J Grimley Evans (chair), Andy Haines, Carol Brayne, Karen Luker, and Madge Vickers.

Contributors: AJM, PW, BA, and AF designed the winter mortality study. PM and RSK collected data on flu vaccination, PHLS flu counts, and meteorological data. SP and BA carried out the statistical analyses. PW wrote the paper. All authors contributed critical comments to the paper. AF is the principal investigator of the MRC trial of assessment and management of older people in the community. $\mathrm{PW}$ is the principal guarantor of the paper. Funding: UK Medical Research Council grants G9900506 and G9223939; and Departments of Health and the Scottish office. PW was supported by a Public Health Career Scientist Award (NHS Executive, CCB/BS/ PHCS031), and PM by project funding from the Wellcome Trust (No 051637).

Competing interests: None declared.

Ethical approval: The relevant local research ethics committees approved the study.

1 Curwen M. Excess winter mortality: a British phenomenon? Health Trends 1990/91:22:169-75

2 Wilkinson P, Landon M, Armstrong B, Stevenson S, McKee M. Cold comfort: the socia and environmental determinants of excess winter death in England, 1986-1996. York: Joseph Rowntree Foundation; 2001

3 Laake K, Sverre JM. Winter excess mortality: a comparison between Norway and England plus Wales. Age Ageing 1996;25:343-8.
4 Pattenden S, Nikiforov B, Armstrong B. Mortality and temperature in Sofia and London. J Epidemiol Community Health 2003;57:628-33.

5 Armstrong B, Wilkinson P, Stevenson S. Identifying components of seasonal variation in mortality. Epidemiology 2000;11:S113

6 McKee C. Deaths in winter: can Britain learn from Europe? Eur J Epidemiol 1989;5:178-82.

7 Eurowinter Group. Cold exposure and winter mortality from ischaemic heart disease, cerebrovascular disease, respiratory disease, and all causes in warm and cold regions of Europe. Lancet 1997;349:1341-6.

8 Fletcher A, Jones D, Bulpitt C, Tulloch A. The MRC Trial of assessment and management of older people in the community: objectives, design and interventions. BMC Health Serv Res 2002;2:21.

9 Carstairs V, Morris R. Deprivation and health in Scotland. Health Bull Edinb 1991;48:162-175.

10 Schwartz J, Spix C, Touloumi G, Bacharova L, Barumamdzadeh T, le Tertre A, et al. Methodological issues in studies of air pollution and daily counts of deaths or hospital admissions. J Epidemiol Community Health 1996;50(suppl 1):S3-11.

11 Bruzzi P, Green SB, Byar DP, Brinton LA, Schairer C. Estimating the population attributable risk for multiple risk factors using case-control data. Am J Epidemiol $1985 ; 122: 904-14$.

12 Huber P. Robust statistics. New York: John Wiley, 1981.

13 Sheth T, Nair C, Muller J, Yusuf S. Increased winter mortality from acute myocardial infarction and stroke: the effect of age. J Am Coll Cardiol 1999:33:1916-9.

14 Aylin P, Morris S, Wakefield J, Grossinho A, Jarup L, Elliott P. Temperature, housing, deprivation and their relationship to excess winter mortality in Great Britain, 1986-1996. Int J Epidemiol 2001;30:1100-8.

15 Carstairs V. Deprivation indices: their interpretation and use in relation to health.J Epidemiol Community Health 1995;49(suppl 2):S3-8.

16 Lawlor DA, Harvey D, Dews HG. Investigation of the association between excess winter mortality and socio-economic deprivation.J Public Health Med 2000;22:176-81.

17 Shah S, Peacock J. Deprivation and excess winter mortality. J Epidemiol Communit Health 1999;53:499-502.

18 van Rossum CT, Shipley MJ, Hemingway H, Grobbee DE, Mackenbach JP, Marmot MG. Seasonal variation in cause-specific mortality: are there high-risk groups? 25-year follow-up of civil servants from the first Whitehall study. Int J Epidemiol 2001:30:110916.

19 Keatinge WR, Coleshaw SR, Holmes J. Changes in seasonal mortalities with improvement in home heating in England and Wales from 1964 to 1984. Int J Biometeorol ment in home

20 Woodhouse PR, Khaw KT, Plummer M. Seasonal variation of blood pressure and its relationship to ambient temperature in an elderly population. J Hypertens 1993;11:1267-74.

21 Stout RW, Crawford VL, McDermott MJ, Rocks MJ, Morris TC. Seasonal changes in haemostatic factors in young and elderly subjects. Age Ageing 1996;25:256-8.

22 Bokenes L, Alexandersen TE, Osterud B, Tveita T, Mercer JB. Physiological and haematological responses to cold exposure in the elderly. Int I Circumpolar Health 2000;59:216-21.

23 Neild PJ, Syndercombe Court D, Keatinge WR, Donaldson GC, Mattock M, Caunce M. Cold-induced increases in erythrocyte count, plasma cholesterol and plasma fibrinogen of elderly people without a comparable rise in protein C or factor X. Clin Sci (Lond) 1994:86:43-8

24 Smolander J. Effect of cold exposure on older humans. Int J Sports Med 2002;23:86-92. 25 Goodwin J, Taylor RS, Pearce VR, Read KL. Seasonal cold, excursional behaviour, clothing protection and physical activity in young and old subjects. Int J Circumpolar Health 2000;59:195-203.

(Accepted 3 June 2004)

doi $10.1136 /$ bmj.38167.589907.55

London School of Hygiene and Tropical Medicine, London WC1E 7HT

Paul Wilkinson senior lecturer

Sam Pattenden lecturer

Ben Armstrong reader

Astrid Fletcher professor

R Sari Kovats lecturer

Punam Mangtani lecturer

Anthony J McMichael professor

Correspondence to: P Wilkinson paul.wilkinson@1shtm.ac.uk 